\title{
Investigating the landscape of physics laboratory instruction across North America
}

\author{
N. G. Holmes $\odot^{1, *}$ and H. J. Lewandowski $\odot^{2,3, \uparrow}$ \\ ${ }^{1}$ Laboratory of Atomic and Solid State Physics and Department of Physics, Cornell University, \\ Ithaca, New York 14850, USA \\ ${ }^{2}$ Department of Physics, University of Colorado, Boulder, Colorado 80309, USA \\ ${ }^{3}$ JILA, National Institute of Standards and Technology and University of Colorado, \\ Boulder, Colorado 80309, USA
}

(Received 10 September 2020; accepted 30 November 2020; published 21 December 2020)

\begin{abstract}
Physics lab instruction is evolving in response to changing technology, a desire to better prepare students for diverse careers, and renewed focus from physics education researchers. To prepare researchers to evaluate progress in instructional labs in the future, this study set out to understand the current state of instructional physics labs in North America. Using information collected from instructors intending to use two research-based lab assessments, we evaluate the reach, organization, goals, and pedagogies from over 200 unique instructional lab courses at over 100 institutions. We find significant diversity in all aspects evaluated, with some trends in course pedagogy based on course goals and level. Namely, courses that aim to reinforce concepts, develop lab skills, or do both incorporate varied levels of agency and modeling in their instruction, with differences in first year and beyond-first year courses. We hope these analyses will be useful for instructors to situate their own courses in the national landscape and for researchers to evaluate changes in lab instruction in the future.
\end{abstract}

DOI: $10.1103 /$ PhysRevPhysEducRes.16.020162

\section{INTRODUCTION}

Physics education researchers, lab instructors, and professional societies are paying renewed attention to lab instruction, particularly questioning the goals for labs and effective practices for achieving those goals [1-5]. Despite relatively little research evaluating lab instruction [4,6], there appears to be broad dissatisfaction with traditional (highly structured and confirmatory) labs [5,7]. Many institutions are calling for change-urging for labs to provide more authentic researchlike experiences [5]. Before embarking on a coordinated process to improve labs broadly, we seek to first understand the current state of lab education across North America using data from 130 institutions and 228 unique lab courses.

\section{MOTIVATION}

Many institutions are rethinking their learning goals and pedagogies in physics labs at all levels. This is indicated by, for example, increasing participation in

\footnotetext{
*ngholmes@cornell.edu
}

†lewandoh@colorado.edu

Published by the American Physical Society under the terms of the Creative Commons Attribution 4.0 International license. Further distribution of this work must maintain attribution to the author(s) and the published article's title, journal citation, and DOI. lab-focused sessions at American Association of Physics Teachers (AAPT) conferences, the relatively new BeyondFirst-Year Lab conference series hosted by the Advanced Laboratory Physics Association (ALPhA; initiated in 2012), the publishing of an updated set of recommendations for physics lab curricula by the AAPT [1], as well as our limited, personal interactions with instructors across the United States and abroad.

This emergence of interest is coupled to an upsurge in research on physics lab instruction. A search of the journal Physical Review Physics Education Research (and the earlier, corresponding Special Topics journal) found only 20 papers published in the ten years before 2015 that included "laboratory" or "lab" in the abstract or title. Since 2015, 47 such papers have been published (in half the time). We use 2015 as a benchmark because the Physics Education Research Conference focused on lab instruction that year and the AAPT released their new set of recommendations for physics lab curricula [1].

In addition to a change in number, there has also been a change in focus. Prior to 2015, articles on lab instruction focused on impacts of labs on students' conceptual knowledge [8-16], attitudes and epistemologies [17,18], understanding of measurement and uncertainty $[19,20]$, and experimentation skills and abilities [21,22]. Limited work also explored lab teaching assistants (TAs) [23-25] and the use of technology in lab [13,14,26,27],

Since 2015, many publications have focused on these same topics: impacts of labs on students' conceptual 
knowledge [28,29], attitudes and epistemologies [30-43], understanding of measurement and uncertainty [44], lab TAs $[45,46]$, and technology $[29,43,47-50]$. However, much more work has focused on development of students' experimentation skills, with specific focus on writing and communication skills [51-53], data analysis skills [54], and various reasoning, modeling, and critical thinking skills [48,55-67]. Additional topics have also emerged, such as impacts of labs on issues of gender and equity $[31,38,68-$ 70]. We recognize that this list of physics lab-focused publications is not comprehensive. The list does, however, provide a glimpse at how research on labs in physics education is evolving.

This increase in attention to lab courses suggests that instruction in labs is also evolving, but does not indicate what is actually happening in the thousands of lab courses around the country. Through the results presented in this paper, we aim to begin to answer important questions about the state of lab instruction in North America: What are the common goals of physics lab courses? What kinds of pedagogies are typically being employed? We hope that evaluating the current landscape of lab instruction will be a productive resource as change efforts develop, and allow researchers and stakeholders in the future to look back and understand how research and dissemination efforts affected lab instruction. Analogous kinds of "status quo" evaluations have recently been carried out to understand how instructors use and/or teach computation in physics instruction $[71,72]$. Researchers are now using that information to design materials and resources to support instructors in integrating computation into their classes [73]. In contrast, researchers are now exploring the degree to which instructors currently teach with traditional versus active learning instructional strategies [74]. Without a benchmark from a decade ago, however, it is unclear how instruction has changed.

Research on lab instruction is too limited for us to say precisely what methods are better for the broad range of courses, goals, and student populations. Thus, as more and more institutions call for change to lab instruction [4-7], we believe it is vital to the PER community that we understand what it is we are asking to change. We hope this paper will provide a productive resource for coordinated change efforts. To be clear, we do not intend to evaluate the labs to indicate what goals or instruction may be effective or ineffective-we simply aim to document what is currently being done.

To achieve this goal, we analyze instructor self-reports about the structure and instruction in their physics lab courses. We draw from a sample likely to be systematically biased towards instructors critically evaluating their labs and therefore not wholly representative of physics lab instruction broadly. The sample, which includes selfreports by instructors aiming to run either the Colorado Learning Attitudes about Science Survey for Experimental
Physics (E-CLASS) [17] or the Physics Lab Inventory of Critical thinking (PLIC) [59], included over 200 unique courses from a range of institutions (from 2-year colleges to Ph.D.-granting institutions), indicating a relatively broad array of instruction.

\section{METHODS}

Data were collected from the Course Information Survey (CIS) [75] used for the E-CLASS and PLIC. Instructors interested in using the assessments complete the CIS with information about their course and their responses to the CIS are used to automatically generate survey links to be shared with students. The CIS also asks about the characteristics of the instructor's course [76], including targeted questions about the pedagogy and instruction in the course (listed in Figure 1). The questions asked for the following:

Basic course and institution information:

- Instructor name and contact information

- Institution name

- Type of institution* (either 2-year college, 4-year college, master's-granting institution, Ph.D.-granting institution, or other)

- Course name and number

- Course level* (either introductory algebra-based, introductory calculus-based, sophomore, junior, senior, graduate, or other)

Information about resources:

- Approximate number of students in the course

- Approximate number of lab sections and instructional staff per section

- Number of scheduled and unscheduled hours per week students spend in the lab and outside of lab (but on lab work)

Information about pedagogy:

- Main purpose of the lab* (either to reinforce physics concepts, develop lab skills, or both about equally)

- Number of weeks spent on guided lab activities

- Number of weeks spent on open-ended lab activities

- Frequency of different types of activities* (See Fig. 1) Questions were mostly free response, with options for closed-response questions indicated with an asterisk $(*)$.

Data included in the study were collected between July 2016 and September 2019 (pre COVID-19 changes). To represent the most recent status of physics lab instruction, we analyzed only the most recent instance of each course from each institution in the dataset. If the most recent version of the course ran both surveys in the same semester, we compared the two instances and took an approximate average of responses; no repeat instances had responses that differed significantly (all differences were within one scale point). We also selected institutions located only in North America, because those educational systems are most similar. 


\begin{tabular}{|c|c|c|c|}
\hline Assigned category & Activity description & Frequency (FY) & Frequency (BFY) \\
\hline \multirow[t]{3}{*}{ Type of investigation } & Verify known physical principles through experimental tests & $3.42 \pm 0.09$ & $3.61 \pm 0.10$ \\
\hline & Discover known physical principles through experimentation & $3.31 \pm 0.08$ & $3.33 \pm 0.09$ \\
\hline & Explore questions to which the answer is unknown to the student & $3.25 \pm 0.08$ & $3.44 \pm 0.10$ \\
\hline \multirow[t]{6}{*}{ Student Agency } & Develop their own research questions & $2.19 \pm 0.09$ & $2.60 \pm 0.10$ \\
\hline & Design their own procedures & $2.86 \pm 0.11$ & $3.07 \pm 0.11$ \\
\hline & Build their own apparatus & $2.33 \pm 0.10$ & $2.60 \pm 0.12$ \\
\hline & Choose their own analysis methods & $2.71 \pm 0.10$ & $3.49 \pm 0.09$ \\
\hline & Troubleshoot problems with the setup or apparatus & $3.19 \pm 0.09$ & $3.95 \pm 0.09$ \\
\hline & Work in groups with other students & $4.82 \pm 0.04$ & $4.54 \pm 0.10$ \\
\hline \multirow[t]{7}{*}{ Modelling } & Develop mathematical models for the system being studied & $2.99 \pm 0.08$ & $3.33 \pm 0.09$ \\
\hline & Develop conceptual models for the system being studied & $3.10 \pm 0.08$ & $3.48 \pm 0.09$ \\
\hline & Develop mathematical models for the measurement tools being used & $2.31 \pm 0.08$ & $2.83 \pm 0.09$ \\
\hline & Develop conceptual models for the measurement tools being used & $2.49 \pm 0.08$ & $3.06 \pm 0.09$ \\
\hline & Use mathematical or conceptual models to make predictions & $3.43 \pm 0.08$ & $3.53 \pm 0.10$ \\
\hline & Refine system to reduce uncertainty & $2.89 \pm 0.10$ & $3.28 \pm 0.09$ \\
\hline & Calibrate measurement tools & $2.66 \pm 0.07$ & $3.30 \pm 0.09$ \\
\hline \multirow{4}{*}{$\begin{array}{l}\text { Data analysis and } \\
\text { visualization }\end{array}$} & Quantify uncertainty in a measurement & $3.74 \pm 0.10$ & $4.27 \pm 0.09$ \\
\hline & Calculate uncertainty using error propagation & $3.12 \pm 0.11$ & $3.93 \pm 0.11$ \\
\hline & Use computers to aid with data analysis and visualization & $3.96 \pm 0.08$ & $4.27 \pm 0.08$ \\
\hline & Use computers to interface with measurement devices & $3.66 \pm 0.08$ & $3.62 \pm 0.10$ \\
\hline \multirow[t]{4}{*}{ Communication } & Give oral presentations & $1.74 \pm 0.09$ & $2.99 \pm 0.15$ \\
\hline & Write lab reports & $3.02 \pm 0.14$ & $4.00 \pm 0.11$ \\
\hline & Maintain lab notebooks & $2.91 \pm 0.14$ & $4.35 \pm 0.12$ \\
\hline & Read journal articles & $1.30 \pm 0.06$ & $2.59 \pm 0.11$ \\
\hline
\end{tabular}

FIG. 1. Average frequency with which students engage in various activities in the lab courses (darker shading means more frequent and values are means \pm standard errors). Instructors could select from never (1), rarely (2), sometimes (3), often (4), or always (5).

The final dataset included 134 first-year (FY) courses and 94 beyond first-year (BFY) courses, including courses from two- and four-year colleges and master's- and Ph.D.granting institutions (Table I). We compare the number of each institution type in the dataset relative to the national numbers, which shows that we notably undersample twoyear and four-year institutions. We separated courses at the FY and BFY levels due to differences in student populations: FY-level courses have students with a range of majors and BFY-level courses typically have majority physics majors. The different student populations typically motivate different goals, course sizes, number and types of instructional staff, and course structure.

We summarized the courses' basic characteristics by plotting distributions and calculating descriptive statistics. Figure 1 shows the average frequency with which FY- and BFY-level courses had students engage in various instructional activities. Table I shows the number of courses from different types of institutions and the average personnel and time spent in lab.
TABLE I. Summary details about the courses at the first-year and beyond first-year levels included in the dataset.

\begin{tabular}{lccccc}
\hline \hline & \multicolumn{2}{c}{ No. courses } & & \multicolumn{2}{c}{ No. institutions ${ }^{\mathrm{a}}$} \\
\cline { 2 - 3 } \cline { 5 - 6 } Institution-type & $\mathrm{FY}$ & $\mathrm{BFY}$ & & Dataset & Nationally \\
\hline 2-year college & 14 & 1 & & 14 & 1063 \\
4-year college & 50 & 38 & & 57 & 503 \\
Master's granting & 8 & 12 & & 13 & 57 \\
Ph.D. granting & 62 & 43 & & 46 & 201 \\
\hline \hline Average no. personnel (SD) & & FY & BFY \\
\hline Students per course & & & $178(263)$ & $31(47)$ \\
Students per section & & & $23(23)$ & $15(11)$ \\
Instructional staff per section & & $1.5(0.8)$ & $1.94(1.4)$ \\
\hline Average time in lab per week (SD) & & \\
\hline Scheduled & & $2.56(0.14)$ & $3.48(1.59)$ \\
Unscheduled & & $0.72(0.43)$ & $1.80(3.00)$ \\
\hline
\end{tabular}

\footnotetext{
${ }^{\mathrm{a}}$ The number of institutions nationally were retrieved from AIP statistics [77,78].

${ }^{\mathrm{b}}$ An outlying data point of $35 \mathrm{~h}$ was removed from the dataset.
} 
We performed a factor analysis to aggregate the responses to the pedagogy questions about the frequency with which students engage in various types of activities in each lab course. We first performed a confirmatory factor analysis using the categories assigned to each item by the creators of the E-CLASS (the first column in Fig. 1). We excluded the "type of investigation" questions (i.e., what experiments students conducted), as these differed conceptually from the subsequent items (i.e., how students conduced experiments). The confirmatory factor analysis was not a good fit to the data according to standard quantitative fit statistics. Thus, we next performed an exploratory factor analysis, which indicated that a fivefactor model was best fitting to the data (as per the "elbow" in a scree plot). The factor structure was quite similar to the predefined model used in the confirmatory analysis, but indicated that several of the items did not fit the factor structure (namely, "work in groups with other students," "refine system to reduce uncertainty," and "calibrate measurement tools"). We then used a confirmatory factor analysis with the model recommended from the exploratory factor analysis, but this did not converge. Inspection of the raw distributions indicated that the communication items deviated significantly from Gaussian and two of the factors had only two items, which we believe resulted in the convergence issues. In the final analysis, we used a twofactor structure using the items that consistently factored together throughout the analysis.

The items associated with each factor are shown in Table II along with their factor loadings. We named the two factors "agency" and "modeling," respectively, based on the original rough categorization. The fit statistics indicate that the model was a good fit to the data: the Tucker Lewis index was 0.982 ( $>0.90$ satisfactory), the comparative fit index was 0.986 ( $>0.90$ satisfactory), the root mean square error of approximation was $0.096(<0.08$ acceptable), and the standardized root mean square of the residuals was 0.074 ( $<0.08$ acceptable). All fit statistics were improved in the final model over the previous models.
The final factor analysis aggregated the pedagogy items into two factors: one describing student agency (e.g., frequency with which students developed their own research questions or designed their own procedures) and one describing quantitative and conceptual modeling practices (e.g., frequency with which students developed mathematical or conceptual models, respectively, for the physical or measurement systems). In the results, we show the distribution of responses for these two factors and compare between FY- and BFY-level courses with various instructional goals. Factor scores are calculated using the final model from the factor analysis, where each course's factor score is a linear combination of their values for each variable in that factor, weighted by each variables factor loading. The factor scores are normalized to have mean equal to zero and standard deviation equal to one, relative to the whole population. We then performed a regression analysis to compare the factor scores according to lab purpose (whether to reinforce concepts, develop skills, or do both), course level (either FY or BFY), and an interaction between lab purpose and course level.

\section{RESULTS}

We summarize the analysis of the CIS responses in several subcategories.

\section{A. Course organization}

The basic organization of the lab courses varied widely. The number of students in each course ranged from 2 to 2000 students. The average number of students in each course was $178 \pm 263$ at the FY level and $31 \pm 47$ at the BFY level (means \pm standard deviation). The number of students per section was typically between 10 and 50 students, with one to two instructional staff per section. FYlevel lab sessions were typically 2 or $3 \mathrm{~h}$ in length, while BFY-level lab sessions ranged from 3 to $6 \mathrm{~h}$.

TABLE II. Factor loadings for the two-factor confirmatory factor analysis to aggregate responses to the frequency items related to student agency and modeling.

\begin{tabular}{llc}
\hline \hline Factor & \multicolumn{1}{c}{ Item } & Factor loading \\
\hline Agency & Develop their own research questions & 0.800 \\
& Design their own procedures & 0.897 \\
& Build their own apparatus & 0.768 \\
& Choose their own analysis methods & 0.800 \\
& Troubleshoot problems with the setup or apparatus & 0.683 \\
& Refine system to reduce uncertainty & 0.720 \\
Modeling & Develop mathematical models for the system being studied & 0.842 \\
& Develop conceptual models for the system being studied & 0.781 \\
& Develop mathematical models for the measurement tools being used & 0.859 \\
& Develop conceptual models for the measurement tools being used & 0.791 \\
& Use mathematical or conceptual models to make predictions & 0.563 \\
\hline \hline
\end{tabular}




\section{B. Course goals}

Nearly half the FY-level courses (46\%) aimed to both develop lab skills and reinforce physics concepts, $20 \%$ aimed to exclusively reinforce concepts, and 34\% aimed to exclusively develop lab skills. At the BFY level, in contrast, over half the courses (53\%) in the dataset aimed to exclusively develop lab skills, while the other half aimed to both develop lab skills and reinforce concepts (44\%). Only three BFY-level courses in the dataset aimed to exclusively reinforce physics concepts.

The courses at different levels and with different lab goals also differed in their use of guided or open-ended investigations (Fig. 2). At the FY level, very few of the courses involved multiple weeks of open-ended activities or projects. In fact, almost $90 \%$ of the FY-level classes that aimed to exclusively reinforce concepts or to both develop lab skills and reinforce concepts had zero weeks of

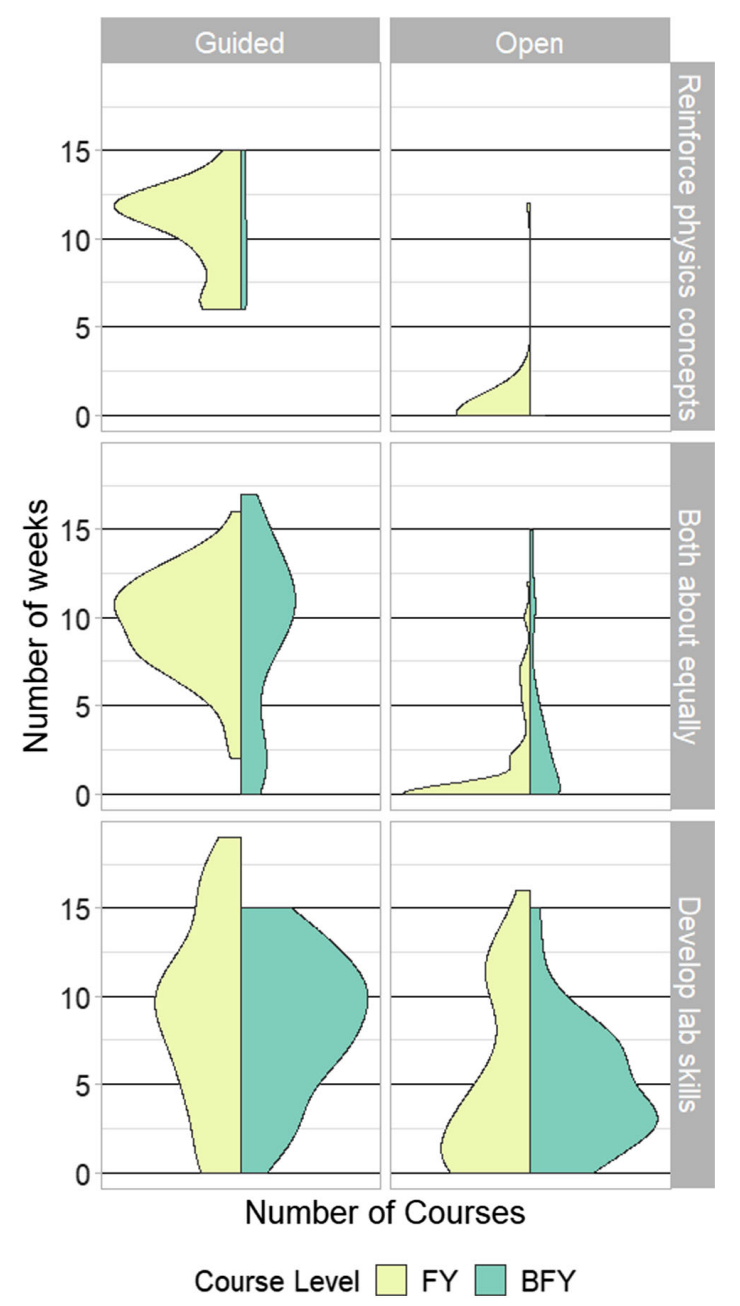

FIG. 2. Number of weeks spent in FY- and BFY-level courses on guided lab activities or open-ended lab activities. Courses are also split out by the course goal (i.e., primary purpose). Instructors may have spent a single week on both guided and unguided activities, so we included only the raw data rather than normalizing by the total number of weeks. open-ended investigations. FY-level labs aiming to exclusively develop skills were much more varied in their use of guided and open-ended activities. Similar patterns emerged in the BFY-level courses, though approximately one-third of the BFY-level courses aiming to exclusively develop skills included open-ended activities or projects in at least five of the class weeks. Only $36 \%$ of the BFY-level courses that aimed to both develop lab skills and reinforce physics concepts had zero weeks of open-ended investigations (compared to $90 \%$ at the FY level).

The types of investigations students pursued also aligned with the lab goal. Of the labs aiming to exclusively reinforce physics concepts, over $90 \%$ (all but two) always or often used investigations to verify known physical principles. Only $20 \%$ of the labs aiming to exclusively reinforce physics concepts ( 6 courses) always or often used investigations where students explored questions to which the answers were unknown. Labs aiming to exclusively

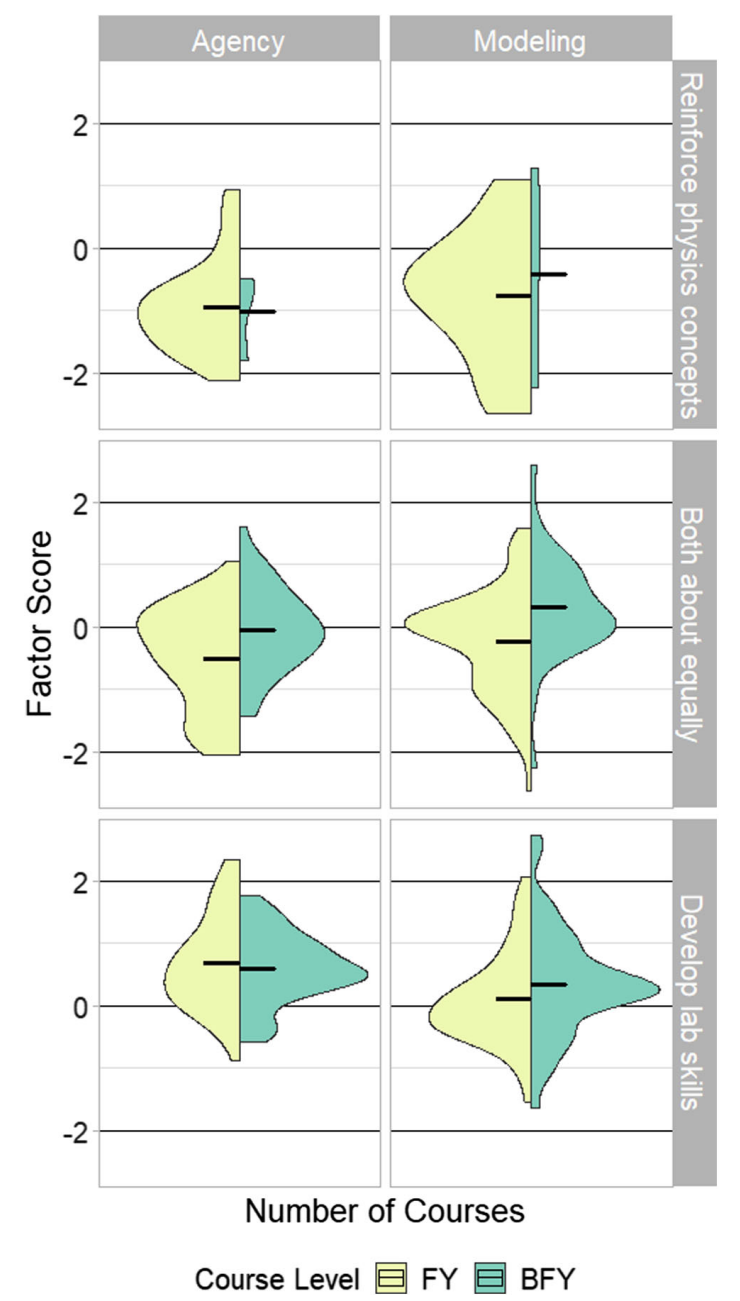

FIG. 3. Distribution of scores on the agency and modeling factors for courses broken out by course level and course goal. Higher factor scores indicate more frequent use of the items loaded on to that factor. The horizontal black lines indicate the means of each distribution. 
TABLE III. Post hoc pairwise comparisons between course levels and purposes on each of the items on the agency and modeling factors. Note that the small number of BFY-level courses exclusively aiming to reinforce concepts make these comparisons unreliable [indicated with the question marks above the (in)equalities].

\begin{tabular}{|c|c|c|}
\hline Factor & Item & BFY level \\
\hline Agency & $\begin{array}{l}\text { Develop their own research questions } \\
\text { Design their own procedures } \\
\text { Build their own apparatus } \\
\text { Choose their own analysis methods } \\
\text { Troubleshoot problems with the setup or apparatus } \\
\text { Refine system to reduce uncertainty }\end{array}$ & 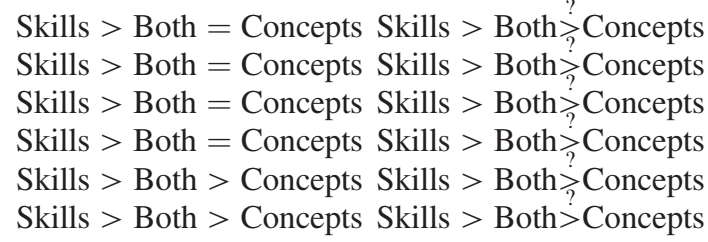 \\
\hline Modeling & $\begin{array}{l}\text { Develop mathematical models for the system being studied } \\
\text { Develop conceptual models for the system being studied } \\
\text { Develop mathematical models for the measurement tools being used } \\
\text { Develop conceptual models for the measurement tools being used } \\
\text { Use mathematical or conceptual models to make predictions }\end{array}$ & $\begin{aligned} & \text { Skills }>\text { Both }>\text { Concepts Skills }=\text { Both } \stackrel{?}{=} \text { Concepts } \\
& \text { Skills }=\text { Both }>\text { Concept Skills }=\text { Both } \stackrel{?}{=} \text { Concepts } \\
& \text { Skills }>\text { Both }>\text { Concepts Skills }=\text { Both }>\text { Concepts } \\
& \text { Skills }=\text { Both }>\text { Concepts Skills }=\text { Both } \stackrel{?}{>} \text { Concepts } \\
& \text { Skills }=\text { Both }>\text { Concepts Skills }=\text { Both }>\text { Concepts }\end{aligned}$ \\
\hline
\end{tabular}

develop lab skills were divided according to how frequently they used investigations to verify known physical principles (30\% indicating rarely or never, sometimes, or often or always). In contrast, about $67 \%$ of skills-based labs always or often used investigations where the answers were unknown to students. For labs that aimed to both reinforce concepts and develop lab skills, 70\% always or often used investigations to verify known principles and $35 \%$ always or often used investigations where the answers were unknown to students.

\section{Course pedagogies}

Figure 1 shows the average frequency with which students engaged in various lab activities, where higher averages (also indicated by darker shading) refer to more frequent use in the course. Compared to FY-level courses, courses at the BFY-level reported more frequently incorporating all of the activities than FY-level courses (all means are higher in BFY-level courses than FY-level courses). Notably, nearly all courses at the BFY-level always or often involved uncertainty analysis activities, and BFY-level courses more frequently used communication activities. FY-level courses indicated very little exposure to reading scientific journal articles or giving oral presentations. Interfacing with computers, using computers to analyze data, and working in groups were common at both course levels.

To understand the differences between the items in the agency and modeling factors, we use the aggregated scores from the factor analysis. Figure 3 displays violin plots for the factor scores on the $y$ axis, where a higher score represents more frequent engagement in the activities in that factor. The violin plot shows the approximate (unnormalized, but smoothed) histogram for each subset of the

TABLE IV. Regression table indicating effect sizes (and standard errors) for factor scores as a function of course variables. Comparison levels (encoded as 1) are estimated relative to the reference group (FY-level courses aiming to both develop skills and reinforce concepts). Multiple $R^{2}$ is approximately the percent variance explained by the model and the adjusted $R^{2}$ is adjusted for the number of predictors in the model. The Akaike information criterion (AIC) and Bayesion information criterion (BIC) are fit indices using maximum likelihood estimates that penalize for model complexity (BIC more so than AIC).

\begin{tabular}{lcc}
\hline \hline Variable (comparison level) & Agency factor & Modeling factor \\
\hline Intercept & $-0.51(0.09)^{* * *}$ & $-0.23(0.11)^{* *}$ \\
Purpose (Reinforce concepts) & $-0.43(0.17)^{* *}$ & $-0.54(0.20)^{* *}$ \\
Purpose (Develop skills) & $1.20(0.14)^{* * *}$ & $0.35(0.17)^{*}$ \\
Course level (BFY) & $0.47(0.14)^{* *}$ & $0.54(0.17)^{* *}$ \\
Purpose (reinforce concepts): Course level (BFY) & $-0.54(0.46)^{*}$ & $-0.20(0.55)$ \\
Purpose (develop skills): Course level (BFY) & $-0.56(0.21)^{*}$ & $-0.31(0.25)$ \\
Multiple $R^{2}$ & 0.42 & 0.17 \\
Adjusted $R^{2}$ & 0.41 & 0.14 \\
AIC & 505 & 584 \\
BIC & 529 & 608 \\
\hline \hline
\end{tabular}

\footnotetext{
$* p<0.05$.

$* * p<0.01$.

$* * * p<0.001$.
} 
data (with FY-level courses on the left and BFY-level courses on the right), with the mean plotted within each distribution.

From Fig. 3, we see that BFY-level courses had higher factor scores on both the agency and modeling factors than FY-level courses overall. Furthermore, courses aiming to exclusively develop lab skills more often included activities that afforded student agency and that incorporated modeling activities as compared to courses aiming to exclusively reinforce physics concepts. This trend was the same for both FY- and BFY-level courses and confirmed through ordinary least-squares regression (Table IV). Post hoc comparisons found that no individual items were responsible for these trends (Table III).

We find that at the FY level courses aiming to both reinforce concepts and develop lab skills behaved more similarly to courses aiming to exclusively reinforce concepts in terms of agency and quantitative modeling, but more similarly to courses aiming to exclusively develop lab skills in terms of conceptual modeling. The outcomes of these comparisons are summarized in Table III. Too few BFY-level courses aimed to exclusively reinforce concepts, making those comparisons unreliable.

The results of the regression analysis are in Table IV.

\section{DISCUSSION}

From the analysis of the CIS dataset for the E-CLASS and the PLIC, we have provided a glimpse of the landscape of lab instruction across North America. The results show that the impacts of lab instruction are far reaching, involving thousands of students each semester. The number of unique classes in our sample (over 200 from a diverse range of institutions) demonstrates, simply by opting to run the E-CLASS or PLIC in their classes, that a large number of instructors and institutions are critically evaluating their lab instruction.

The results also indicate that lab instruction is heterogeneous across institutions, both in terms of the goals and pedagogies. While many courses at both levels aimed to develop lab skills, most FY-level courses aimed to reinforce concepts, though often in addition to teaching skills. This may be an underestimate given that the sample likely skews to courses aiming to teach experimentation skills over concepts (because the data came from instructors interested in evaluating their labs based on students' skills and attitudes towards experimental physics, rather than conceptual understanding).

The goals of the courses were closely related to the structure of the activities and the types of investigations students pursued. Courses aiming to reinforce physics concepts (including when also aiming to develop lab skills) were more likely to conduct investigations to verify known physical principles, while labs exclusively aiming to develop lab skills were more likely to conduct experiments where outcomes were unknown to the students. The majority of the lab courses at the FY level were heavily guided with little use of open-ended investigations. FY-level labs that aimed to reinforce concepts (including when also aiming to develop lab skills) were almost exclusively guided, with no time on open-ended activities. BFY-level courses were generally more varied in their structure, but still included many weeks of guided activities.

We also saw that labs aiming to develop lab skills included more frequent use of activities that afforded students agency and engaged students in modeling compared with labs aiming to reinforce concepts, regardless of the course level. BFY-level courses, in general, included more frequent use of activities that afforded agency and engaged in modeling compared with FY-level courses. Item-by-item comparisons indicated that no individual items contributed to these results in particular. They suggest, however, that BFY-level courses aiming to both develop lab skills and reinforce concepts are similar to courses aiming to exclusively develop lab skills (particularly on modeling items). In contrast, FY-level courses aiming to both develop lab skills and reinforce concepts are more similar to courses aiming to exclusively reinforce concepts on agency items, but more similar to courses aiming to exclusively develop lab skills on modeling items.

As already identified, the data are primarily limited by the nature of the data sources. While the CIS data from the E-CLASS and PLIC were a convenient and relatively broad data source, they still represent a select sample of instructional labs run by instructors interested in evaluating their instruction through experimentation-focused surveys (as opposed to conceptual physics surveys). The data are also made up of self-report responses, which may or may not accurately reflect the structure and pedagogy of the courses. Obtaining more precise and accurate data would have been impractical for such a large dataset, but the observations here motivate more detailed analyses in the future (e.g., analysis of lab course syllabi or instructional materials).

Despite these limitations, the results present a baseline for understanding the landscape of lab instruction in North America, from which researchers and administrators can motivate large-scale changes. As described in the introduction, more attention has been paid to physics lab instruction in the PER literature, particularly related to developing student skills and exploring issues of gender and equity. Researchers can use these results to situate their studies in the national landscape or to identify possible variables worthy of study. For example, given that the different lab goals align with different types of pedagogies, how might we distinguish the role of the instructional activities from the overarching learning objects in exploring student learning? Or, given that different pedagogies are employed at different course levels, what forms of agency and modeling are appropriate for students at each level?

The heterogeneity we observe of the labs (consistent with lack of consensus goals and pedagogy previously 
reported [7,79]) is an important variable to consider in institutional change efforts. Historically, lab instruction has often been reformed on a course-by-course or institutionby-institution basis [80]. Without a broad perspective, such changes do not become widespread. We hope that the analysis presented here will help support national, coordinated, and coherent movements to change lab instruction that recognizes the existing status quo.

\section{ACKNOWLEDGMENTS}

We thank the many people who worked on developing the CIS and automated data collection systems for ECLASS and PLIC including John Aiken, Dimitri DounasFrazer, Robert Hobbs, Benjamin Pollard, Cole Walsh, Nathan Welch, and Bethany Wilcox. We acknowledge support from NSF PHY-1734006 and NSF DUE-1611482.
[1] American Association of Physics Teachers, AAPT Recommendations for the Undergraduate Physics Laboratory Curriculum, Tech. Rep. (American Association of Physics Teachers, College Park, MD, 2014).

[2] Advanced laboratory physics association, https://advlab .org/, accessed: 2020-02-19.

[3] P. Heron and L. E. McNeil, Phys21: Preparing Physics Students for 21st Century Careers, Tech. Rep. (Joint Task Force on Undergraduate Physics Programs American Physical Society and American Association of Physics Teachers, College Park, MD, 2016).

[4] S. Laursen, Levers for Change: An Assessment of Progress on Changing STEM Instruction, Tech. Rep. (American Association for the Advancement of Science, Washington, DC, 2019).

[5] The Presidents Council of Advisors on Science and Technology, Engage to Excel: Producing One Million Additional College Graduates with Degrees in Science, Technology, Engineering, and Mathematics (Executive Office of the President, Washington, DC, 2012).

[6] Discipline-Based Education Research: Understanding and Improving Learning in Undergraduate Science and Engineering, Tech. Rep. (Committee on the Status, Contributions, and Future Directions of Discipline-Based Education Research; Board on Science Education; Division of Behavioral and Social Sciences and Education; National Research Council, Washington, DC, 2012).

[7] America's Lab Report: Investigations in High School Science, Tech. Rep. (Committee on High School Science Laboratories: Role and Vision; National Research Council, Washington, DC, 2005).

[8] M. J. B. de Almeida, A. Salvador, and M. M. R. Costa, Analogy for Drude's free electron model to promote students' understanding of electric circuits in lower secondary school, Phys. Rev. ST Phys. Educ. Res. 10, 020118 (2014).

[9] M. M. Wooten, A. M. Cool, E. E. Prather, and K. D. Tanner, Comparison of performance on multiple-choice questions and open-ended questions in an introductory astronomy laboratory, Phys. Rev. ST Phys. Educ. Res. 10, 020103 (2014).

[10] B. Thacker, H. Dulli, D. Pattillo, and K. West, Lessons from a large-scale assessment: Results from conceptual inventories, Phys. Rev. ST Phys. Educ. Res. 10, 020104 (2014).
[11] J. Benegas and J. S. Flores, Effectiveness of tutorials for introductory physics in argentinean high schools, Phys. Rev. ST Phys. Educ. Res. 10, 010110 (2014).

[12] F. Goldberg, E. Price, S. Robinson, D. Boyd-Harlow, and M. McKean, Developing the learning physical science curriculum: Adapting a small enrollment, laboratory, and discussion based physical science course for large enrollments, Phys. Rev. ST Phys. Educ. Res. 8, 010121 (2012).

[13] J. J. Chini, A. Madsen, E. Gire, N. S. Rebello, and S. Puntambekar, Exploration of factors that affect the comparative effectiveness of physical and virtual manipulatives in an undergraduate laboratory, Phys. Rev. ST Phys. Educ. Res. 8, 010113 (2012).

[14] G. Martínez, F. L. Naranjo, A. L. Pérez, M. I. Suero, and P. J. Pardo, Comparative study of the effectiveness of three learning environments: Hyper-realistic virtual simulations, traditional schematic simulations and traditional laboratory, Phys. Rev. ST Phys. Educ. Res. 7, 020111 (2011).

[15] M. Plomer, K. Jessen, G. Rangelov, and M. Meyer, Teaching physics in a physiologically meaningful manner, Phys. Rev. ST Phys. Educ. Res. 6, 020116 (2010).

[16] T. Fredlund, C. Linder, J. Airey, and A. Linder, Unpacking physics representations: Towards an appreciation of disciplinary affordance, Phys. Rev. ST Phys. Educ. Res. 10, 020129 (2014).

[17] B. M. Zwickl, T. Hirokawa, N. Finkelstein, and H. J. Lewandowski, Epistemology and expectations survey about experimental physics: Development and initial results, Phys. Rev. ST Phys. Educ. Res. 10, 010120 (2014).

[18] P. W. Irving and E. C. Sayre, Conditions for building a community of practice in an advanced physics laboratory, Phys. Rev. ST Phys. Educ. Res. 10, 010109 (2014).

[19] T. S. Volkwyn, S. Allie, A. Buffler, and F. Lubben, Impact of a conventional introductory laboratory course on the understanding of measurement, Phys. Rev. ST Phys. Educ. Res. 4, 010108 (2008).

[20] M. C. Wittmann, J. T. Morgan, and R. E. Feeley, Laboratory-tutorial activities for teaching probability, Phys. Rev. ST Phys. Educ. Res. 2, 020104 (2006).

[21] E. Etkina, A. Karelina, S. Murthy, and M. RuibalVillasenor, Using action research to improve learning and formative assessment to conduct research, Phys. Rev. ST Phys. Educ. Res. 5, 010109 (2009). 
[22] A. Karelina and E. Etkina, Acting like a physicist: Student approach study to experimental design, Phys. Rev. ST Phys. Educ. Res. 3, 020106 (2007).

[23] J. B. Stang and I. Roll, Interactions between teaching assistants and students boost engagement in physics labs, Phys. Rev. ST Phys. Educ. Res. 10, 020117 (2014).

[24] E. A. West, C. A. Paul, D. Webb, and W. H. Potter, Variation of instructor-student interactions in an introductory interactive physics course, Phys. Rev. ST Phys. Educ. Res. 9, 010109 (2013).

[25] R. M. Goertzen, E. Brewe, L. H. Kramer, L. Wells, and D. Jones, Moving toward change: Institutionalizing reform through implementation of the learning assistant model and open source tutorials, Phys. Rev. ST Phys. Educ. Res. 7, 020105 (2011).

[26] S. Chen, H.-C. Lo, J.-W. Lin, J.-C. Liang, H.-Y. Chang, F.-K. Hwang, G.-L. Chiou, Y.-T. Wu, S. W.-Y. Lee, H.-K. $\mathrm{Wu}$, C.-Y. Wang, and C.-C. Tsai, Development and implications of technology in reform-based physics laboratories, Phys. Rev. ST Phys. Educ. Res. 8, 020113 (2012).

[27] N. D. Finkelstein, W. K. Adams, C. J. Keller, P. B. Kohl, K. K. Perkins, N. S. Podolefsky, S. Reid, and R. LeMaster, When learning about the real world is better done virtually: A study of substituting computer simulations for laboratory equipment, Phys. Rev. ST Phys. Educ. Res. 1, 010103 (2005).

[28] N. G. Holmes, J. Olsen, J. L. Thomas, and C. E. Wieman, Value added or misattributed? A multi-institution study on the educational benefit of labs for reinforcing physics content, Phys. Rev. Phys. Educ. Res. 13, 010129 (2017).

[29] S. J. Husnaini and S. Chen, Effects of guided inquiry virtual and physical laboratories on conceptual understanding, inquiry performance, scientific inquiry selfefficacy, and enjoyment, Phys. Rev. Phys. Educ. Res. 15, 010119 (2019).

[30] A. R. Warren, Impact of Bayesian updating activities on student epistemologies, Phys. Rev. Phys. Educ. Res. 16, 010101 (2020).

[31] T. Espinosa, K. Miller, I. Araujo, and E. Mazur, Reducing the gender gap in students' physics self-efficacy in a teamand project-based introductory physics class, Phys. Rev. Phys. Educ. Res. 15, 010132 (2019).

[32] A. J. Mason and C. A. Bertram, Consideration of learning orientations as an application of achievement goals in evaluating life science majors in introductory physics, Phys. Rev. Phys. Educ. Res. 14, 010125 (2018).

[33] D. Hu, B. M. Zwickl, B. R. Wilcox, and H. J. Lewandowski, Qualitative investigation of students' views about experimental physics, Phys. Rev. Phys. Educ. Res. 13, 020134 (2017).

[34] D. Hu and B. M. Zwickl, Examining students' views about validity of experiments: From introductory to Ph.D. students, Phys. Rev. Phys. Educ. Res. 14, 010121 (2018).

[35] D. R. Dounas-Frazer, J. T. Stanley, and H. J. Lewandowski, Student ownership of projects in an upper-division optics laboratory course: A multiple case study of successful experiences, Phys. Rev. Phys. Educ. Res. 13, 020136 (2017).

[36] B. R. Wilcox and H. J. Lewandowski, Developing skills versus reinforcing concepts in physics labs: Insight from a survey of students' beliefs about experimental physics, Phys. Rev. Phys. Educ. Res. 13, 010108 (2017).

[37] B. R. Wilcox and H. J. Lewandowski, Open-ended versus guided laboratory activities: Impact on students' beliefs about experimental physics, Phys. Rev. Phys. Educ. Res. 12, 020132 (2016).

[38] B. R. Wilcox and H. J. Lewandowski, Research-based assessment of students' beliefs about experimental physics: When is gender a factor?, Phys. Rev. Phys. Educ. Res. 12, 020130 (2016).

[39] B. R. Wilcox and H. J. Lewandowski, Improvement or selection? A longitudinal analysis of students' views about experimental physics in their lab courses, Phys. Rev. Phys. Educ. Res. 13, 023101 (2017).

[40] B. R. Wilcox and H. J. Lewandowski, Students' views about the nature of experimental physics, Phys. Rev. Phys. Educ. Res. 13, 020110 (2017).

[41] B. R. Wilcox and H. J. Lewandowski, Students' epistemologies about experimental physics: Validating the Colorado Learning Attitudes about Science Survey for experimental physics, Phys. Rev. Phys. Educ. Res. 12, 010123 (2016).

[42] B. R. Wilcox and H. J. Lewandowski, Developing skills versus reinforcing concepts in physics labs: Insight from a survey of students' beliefs about experimental physics, Phys. Rev. Phys. Educ. Res. 13, 010108 (2017).

[43] J. Haglund, F. Jeppsson, D. Hedberg, and K. J. Schönborn, Students' framing of laboratory exercises using infrared cameras, Phys. Rev. ST Phys. Educ. Res. 11, 020127 (2015).

[44] A. Susac, A. Bubic, P. Martinjak, M. Planinic, and M. Palmovic, Graphical representations of data improve student understanding of measurement and uncertainty: An eye-tracking study, Phys. Rev. Phys. Educ. Res. 13, 020125 (2017).

[45] D. Doucette, R. Clark, and C. Singh, Professional development combining cognitive apprenticeship and expectancyvalue theories improves lab teaching assistants' instructional views and practices, Phys. Rev. Phys. Educ. Res. 16, 020102 (2020).

[46] M. Wilcox, Y. Yang, and J. J. Chini, Quicker method for assessing influences on teaching assistant buy-in and practices in reformed courses, Phys. Rev. Phys. Educ. Res. 12, 020123 (2016).

[47] S.-Y. Lin, J. M. Aiken, D. T. Seaton, S. S. Douglas, E. F. Greco, B. D. Thoms, and M. F. Schatz, Exploring physics students' engagement with online instructional videos in an introductory mechanics course, Phys. Rev. Phys. Educ. Res. 13, 020138 (2017).

[48] M. Vonk, P. Bohacek, C. Militello, and E. Iverson, Developing model-making and model-breaking skills using direct measurement video-based activities, Phys. Rev. Phys. Educ. Res. 13, 020106 (2017).

[49] P. Coppens, J. Van den Bossche, and M. De Cock, Video observation as a tool to analyze and modify an electronics laboratory, Phys. Rev. Phys. Educ. Res. 12, 020121 (2016).

[50] M. K. Pedersen, B. Skyum, R. Heck, R. Müller, M. Bason, A. Lieberoth, and J. F. Sherson, Virtual learning environment for interactive engagement with advanced quantum 
mechanics, Phys. Rev. Phys. Educ. Res. 12, 013102 (2016).

[51] J. R. Hoehn and H. Lewandowski, Framework of goals for writing in physics lab classes, Phys. Rev. Phys. Educ. Res. 16, 010125 (2020).

[52] S. S. Douglas, J. M. Aiken, S.-Y. Lin, E. F. Greco, E. Alicea-Muñoz, and M.F. Schatz, Peer assessment of student-produced mechanics lab report videos, Phys. Rev. Phys. Educ. Res. 13, 020126 (2017).

[53] J. T. Stanley and H. J. Lewandowski, Lab notebooks as scientific communication: Investigating development from undergraduate courses to graduate research, Phys. Rev. Phys. Educ. Res. 12, 020129 (2016).

[54] R. S. Nixon, T. J. Godfrey, N. T. Mayhew, and C. C. Wiegert, Undergraduate student construction and interpretation of graphs in physics lab activities, Phys. Rev. Phys. Educ. Res. 12, 010104 (2016).

[55] E. M. Smith, M. M. Stein, and N. Holmes, How expectations of confirmation influence students' experimentation decisions in introductory labs, Phys. Rev. Phys. Educ. Res. 16, 010113 (2020).

[56] B. Priemer, S. Pfeiler, and T. Ludwig, Firsthand or secondhand data in school labs: It does not make a difference, Phys. Rev. Phys. Educ. Res. 16, 013102 (2020).

[57] N. G. Holmes, B. Keep, and C. E. Wieman, Developing scientific decision making by structuring and supporting student agency, Phys. Rev. Phys. Educ. Res. 16, 010109 (2020).

[58] L. Ríos, B. Pollard, D. R. Dounas-Frazer, and H. J. Lewandowski, Using think-aloud interviews to characterize model-based reasoning in electronics for a laboratory course assessment, Phys. Rev. Phys. Educ. Res. 15, 010140 (2019).

[59] C. Walsh, K. N. Quinn, C. Wieman, and N. Holmes, Quantifying critical thinking: Development and validation of the physics lab inventory of critical thinking, Phys. Rev. Phys. Educ. Res. 15, 010135 (2019).

[60] D. R. Dounas-Frazer, L. Ríos, B. Pollard, J. T. Stanley, and H. Lewandowski, Characterizing lab instructors' selfreported learning goals to inform development of an experimental modeling skills assessment, Phys. Rev. Phys. Educ. Res. 14, 020118 (2018).

[61] J. T. Stanley, W. Su, and H. J. Lewandowski, Using lab notebooks to examine students' engagement in modeling in an upper-division electronics lab course, Phys. Rev. Phys. Educ. Res. 13, 020127 (2017).

[62] K. L. Van De Bogart, D. R. Dounas-Frazer, H. J. Lewandowski, and M. R. Stetzer, Investigating the role of socially mediated metacognition during collaborative troubleshooting of electric circuits, Phys. Rev. Phys. Educ. Res. 13, 020116 (2017).

[63] N. Holmes, D. Kumar, and D. Bonn, Toolboxes and handing students a hammer: The effects of cueing and instruction on getting students to think critically, Phys. Rev. Phys. Educ. Res. 13, 010116 (2017).

[64] D. R. Dounas-Frazer and H. J. Lewandowski, Electronics lab instructors' approaches to troubleshooting instruction, Phys. Rev. Phys. Educ. Res. 13, 010102 (2017).
[65] N. G. Holmes and C. E. Wieman, Examining and contrasting the cognitive activities engaged in undergraduate research experiences and lab courses, Phys. Rev. Phys. Educ. Res. 12, 020103 (2016).

[66] D. R. Dounas-Frazer, K. L. Van De Bogart, M. R. Stetzer, and H. J. Lewandowski, Investigating the role of modelbased reasoning while troubleshooting an electric circuit, Phys. Rev. Phys. Educ. Res. 12, 010137 (2016).

[67] B. M. Zwickl, D. Hu, N. Finkelstein, and H. J. Lewandowski, Model-based reasoning in the physics laboratory: Framework and initial results, Phys. Rev. ST Phys. Educ. Res. 11, 020113 (2015).

[68] K. N. Quinn, M. M. Kelley, K. L. McGill, E. M. Smith, Z. Whipps, and N. G. Holmes, Group roles in unstructured labs show inequitable gender divide, Phys. Rev. Phys. Educ. Res. 16, 010129 (2020).

[69] J. Day, J. B. Stang, N. G. Holmes, D. Kumar, and D. A. Bonn, Gender gaps and gendered action in a first-year physics laboratory, Phys. Rev. Phys. Educ. Res. 12, 020104 (2016).

[70] A. Traxler and E. Brewe, Equity investigation of attitudinal shifts in introductory physics, Phys. Rev. ST Phys. Educ. Res. 11, 020132 (2015).

[71] M. D. Caballero and L. Merner, Prevalence and nature of computational instruction in undergraduate physics programs across the United States, Phys. Rev. Phys. Educ. Res. 14, 020129 (2018).

[72] N. T. Young, G. Allen, J. M. Aiken, R. Henderson, and M. D. Caballero, Identifying features predictive of faculty integrating computation into physics courses, Phys. Rev. Phys. Educ. Res. 15, 010114 (2019).

[73] M. D. Caballero, N. Chonacky, L. Engelhardt, R. C. Hilborn, M. L. del Puerto, and K. R. Roos, PICUP: A community of teachers integrating computation into undergraduate physics courses, Phys. Teach. 57, 397 (2019).

[74] M. Stains et al., Anatomy of STEM teaching in North American universities, Science 359, 1468 (2018).

[75] B. R. Wilcox, B. M. Zwickl, R. D. Hobbs, J. M. Aiken, N. M. Welch, and H. J. Lewandowski, Alternative model for administration and analysis of research-based assessments, Phys. Rev. Phys. Educ. Res. 12, 010139 (2016).

[76] Although we ask for the instructor's name and contact information, our participants are actually the courses, not the instructors.

[77] C. Helba, A. M. Porter, S. Nicholson, and R. Ivie, The Number of Faculty Members in Physics Departments, https://www.aip.org/statistics/reports/number-facultymembers-physics-departments.

[78] S. White and R. Chu, Number of Physics Faculty in TwoYear Colleges, https://www.aip.org/statistics/reports/ number-physics-faculty-two-year-colleges.

[79] A. Hofstein and V. N. Lunetta, The laboratory in science education: Foundations for the twenty-first century, Sci. Educ. 88, 28 (2004).

[80] A. Carter, 150 years later, introductory labs are poised for change, in 2019 American Association of Physics Teachers Summer Meeting, Provo, Utah (unpublished). 